\title{
High-throughput screening of antagonists for the orphan G-protein coupled receptor GPR139
}

\author{
Jia WANG ${ }^{1}$, Lin-yun ZHU ${ }^{1}$, Qing LIU $^{1}$, Morten HENTZER ${ }^{2}$, Garrick Paul SMITH², Ming-wei WANG ${ }^{1, *}$ \\ ${ }^{1}$ The National Center for Drug Screening and the CAS Key Laboratory of Receptor Research, Shanghai Institute of Materia Medica, \\ Chinese Academy of Sciences, Shanghai 201203, China; ${ }^{2}$ Neuroscience Drug Discovery, H Lundbeck A/S, DK-2500 Copenhagen, \\ Denmark
}

\begin{abstract}
Aim: To discover antagonists of the orphan G-protein coupled receptor GPR139 through high-throughput screening of a collection of diverse small molecules.

Methods: Calcium mobilization assays were used to identify initial hits and for subsequent confirmation studies.

Results: Five small molecule antagonists, representing 4 different scaffolds, were identified following high-throughput screening of 16000 synthetic compounds.

Conclusion: The findings provide important tools for further study of this orphan G-protein coupled receptor.
\end{abstract}

Keywords: orphan G-protein coupled receptor; GPR139; high-throughput screening; calcium mobilization assay; antagonist

Acta Pharmacologica Sinica (2015) 36: 874-878; doi: 10.1038/aps.2015.12; published online 1 Jun 2015

\section{Introduction}

G-protein coupled receptors (GPCRs) are the largest family of cell surface communicating molecules, and they play crucial roles in numerous physiological processes and disease states. GPCRs share high levels of homology and contain seven transmembrane helices separated by intra- and extracellular loops ${ }^{[1]}$. They signal via heterotrimeric $G$ proteins composed of $\mathrm{Ga}, \beta$, and $\gamma$ subunits, and there are four major $\mathrm{Ga}$ protein subfamilies: Gq, Gs, Gi, and $\mathrm{G}_{12 / 13}$. The $\mathrm{Gs}$ and $\mathrm{Gi}$ subunits regulate adenyl cyclase activity, whereas the Gq subunit regulates phospholipase $\mathrm{C}$ and the subsequent production of diacylglycerol and inositol phosphate, which initiates calcium release from intracellular stores. The $\mathrm{G}_{12 / 13}$ subunit regulates the activities of the small $G$ protein $\operatorname{RhoA}^{[2]}$.

The human GPR139 gene was identified by searching the GenBank genomic database ${ }^{[2-5]}$. The human GPR139 (also known as hGPRg1 or hGPCR12) protein is a 345-amino acid orphan receptor located on chromosome $16 \mathrm{p} 12.3$. It shares $96 \%$ amino acid homology with murine orthologs ${ }^{[2]}$. Expression studies in mice have revealed that the transcription of GPR139 is more evident in the brain, both in the adult stage and during development ${ }^{[3]}$. Human GPR139 mRNA is pre-

\footnotetext{
* To whom correspondence should be addressed.

E-mail mwwang@simm.ac.cn

Received 2014-10-15 Accepted 2015-01-27
}

dominantly expressed in the fetal and adult central nervous system (CNS), especially in the basal ganglia and the hypothalamus ${ }^{[2,3]}$, which are involved in movement control, regulation of food intake and metabolism ${ }^{[2,3,6]}$. The consistent expression of GPR139 mRNA in the CNS of different species suggests that it plays specific roles in the modulation of brain functions. Thus, it is implicated as a potential drug target for diabetes, obesity and Parkinson's disease.

Understanding the signaling pathway of a receptor is critical for the development of in vitro bioassays to support drug discovery. The signal transduction pathway of GPR139, however, is still not fully defined due to a lack of natural or synthetic ligands.

To date, three groups have reported small molecule ligands for GPR139 (Figure 1). Shi et al identified compound $\mathbf{1}$ as a GPR139 receptor agonist with an $\mathrm{EC}_{50}$ of $39 \mathrm{nmol} / \mathrm{L}$ in a calcium mobilization assay for a CHO-K1 cell line stably expressing the human GPR139 for high-throughput screening (HTS) ${ }^{[7]}$. Isberg et al discovered dipeptides and L-a-amino acids as GPR139 agonists by building a pharmacophore model based on the characterization of 13 compounds reported by Shi et $a l^{[8]}$. Four dipeptides [TyrTrp (2), TyrPhe, TrpTyr, and TyrHis] consisting of aromatic amino acids were obtained. Among them, TyrTrp (2) and TyrPhe satisfied all five elements of the pharmacophore model ${ }^{[9]}$ and therefore displayed the highest potencies $\left(\mathrm{EC}_{50}=160 \mu \mathrm{mol} / \mathrm{L}\right.$ for TyrTrp and $180 \mu \mathrm{mol} / \mathrm{L}$ for 


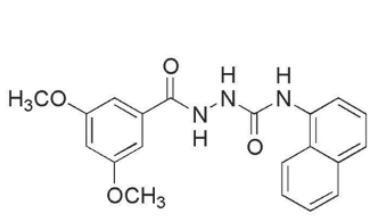

1<smiles>N[C@@H](Cc1c[nH]c2ccccc12)C(=O)O</smiles>

L-Trp

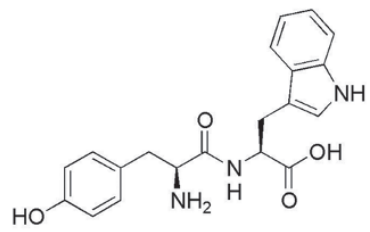

2

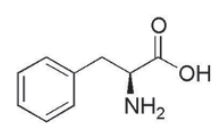

L-Phe
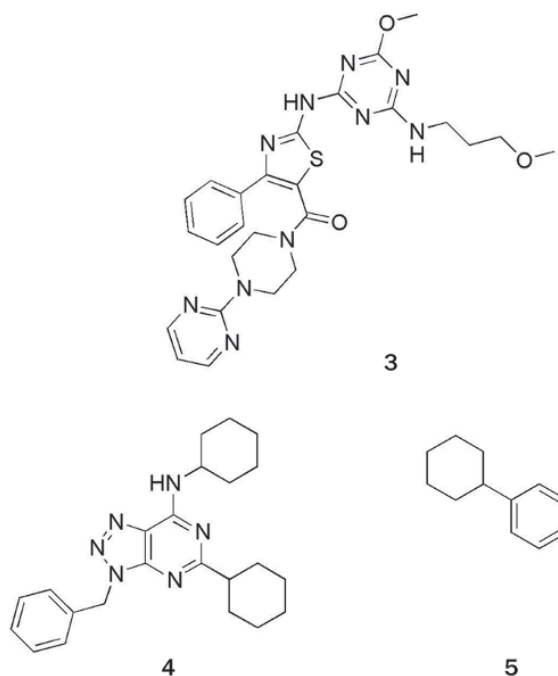

4

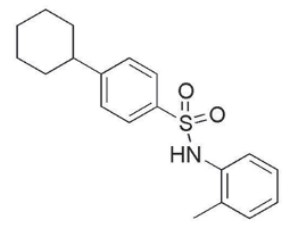

5

Figure 1. Reported small molecule ligands for GPR139.

TyrPhe), whereas TrpTyr lacks a hydrogen bond acceptor element, and TyrHis lacks an aromatic element. In addition, two amino acids, Trp and Phe, and their $L$ - and $D$-isomers were found to activate GPR139 with an $E_{\max }$ similar to compound $\mathbf{1}$.

$\mathrm{Hu}$ et al identified compound 3 as a GPR139 agonist after screening a large library of small molecules ${ }^{[6]}$. Compound 3 specifically increased cAMP levels by 8 - to 10 -fold in cells expressing GPR139 but not in cells expressing GPR142, a GPR139-related receptor with 50\% amino acid identity. Furthermore, this compound was unable to induce $\mathrm{Ca}^{2+}$ mobilization in a fluorescent imaging plate reader (FLIPR) based assay, indicating the absence of a $\mathrm{Ga}_{\mathrm{q}}$-mediated response. Antagonist screening with an identified agonist yielded two classes of compounds, including the triazolopyrimidine series, represented by compound 4 , and the sulfonamide series, represented by compound 5 , which specifically inhibited compound 3 induced cAMP accumulation in GPR139-expressing cells with $\mathrm{IC}_{50}$ values of 0.67 and $0.64 \mu \mathrm{mol} / \mathrm{L}$, respectively.

In this study, we report the identification of four new scaffolds of GPR139 antagonists following high-throughput screening of 16000 synthetic compounds using a calcium mobilization assay.

\section{Materials and methods Materials}

Fluo-4 NW calcium assay kit, F-12 Kaighn's Nutrient Mixture (+L-Glutamine), fetal bovine serum, penicillin-streptomycin, sodium pyruvate, geneticin and $0.5 \%$ trypsin-EDTA were bought from Life Technologies (Carlsbad, CA, USA). DSMO was purchased from Sigma (St Louis, MO, USA) and the assay plates were procured from Corning (Tewksbury, MA, USA). Compound 1 was supplied by H Lundbeck A/S, Denmark.

\section{Cell culture}

CHO-K1 cells stably transfected with human GPR139 was provided by H Lundbeck A/S, Denmark. Cells were maintained in F-12 Kaighn's medium containing 10\% fetal bovine serum (FBS), 100 units/mL penicillin/streptomycin, $1 \mathrm{mmol} / \mathrm{L}$ sodium pyruvate and $0.5 \mathrm{mg} / \mathrm{mL}$ geneticin in a $5 \% \mathrm{CO}_{2}$ incubator.

\section{Compound library}

The compound library used in this study consists of both synthetic and natural compounds. The structural diversity covers heterocycles, lactams, sulfonates, sulfonamides, amines, sencondary amides and natural product-derived compounds. The compounds were highly purified, and the stock was presolubilized in $100 \%$ DMSO prior to application in the HTS campaign, performed with an average concentration of 10 $\mu \mathrm{mol} / \mathrm{L}$ for each compound.

\section{HTS campaign}

The cells mentioned above were seeded in 96-well microtiter plates (Corning; 14000 cells per $100 \mu \mathrm{L}$ growth medium per well) and rested for 45-60 $\mathrm{min}$ at room temperature before incubating at $37^{\circ} \mathrm{C}, 5 \% \mathrm{CO}_{2}$ and $95 \%$ humidity chamber for two days. The dye mix solution was prepared from the Fluo-4 NW calcium assay kit according to the manufacturer's protocol by adding $100 \mathrm{~mL}$ assay buffer (HBSS/HEPS) and $1 \mathrm{~mL}$ probenecid stock solution $(250 \mathrm{mmol} / \mathrm{L})$ to the dye and shaking the resultant solution vigorously for $2 \mathrm{~min}$ (stored in dark).

Upon removal of growth medium $100 \mu \mathrm{L}$ of the dye mix solution was added to each well and incubated for $30 \mathrm{~min}$ at $37^{\circ} \mathrm{C}$, then at room temperature for an additional $45 \mathrm{~min}$ with plate top covered with tinfoil. This was followed by measurement of fluorescence signals in the first column (8 wells) for $10 \mathrm{~s}$ to obtain a baseline, using a FlexStation ${ }^{\mathrm{II}}$ microplate reader (Molecular Devices, Sunnyvale, CA, USA). The library compounds in DMSO $(1 \mathrm{mg} / \mathrm{mL})$ were diluted in the assay buffer and $25 \mu \mathrm{L}$ of which was dispensed to each well (final concentration was approximately $10 \mu \mathrm{mol} / \mathrm{L}$ in $0.5 \%$ DMSO). After the first measurement for $1 \mathrm{~min}$, the plates were incubated for $9 \mathrm{~min}$ at room temperature prior to introduction of the agonist compound 1 ( $25 \mu \mathrm{L}$ at a final concentration of $100 \mathrm{nmol} / \mathrm{L})$ followed by the second measurement for $1 \mathrm{~min}$. Intracellular calcium change was recorded at an excitation wavelength of $485 \mathrm{~nm}$ and an emission wavelength of $535 \mathrm{~nm}$. 


\section{Dose-response study}

Dose-response study was performed essentially as the same as described above except that test compounds were hand-picked (10 mmol/L concentration in DMSO) and serially diluted (1:5) seven times to give a total of eight different concentrations. This reflects a final compound dilution factor ranging from 1:96 to 1:136. For a starting concentration of $10 \mathrm{mmol} / \mathrm{L}$ this corresponded to a concentration range between 103.6 and $80.2 \mu \mathrm{mol} / \mathrm{L}$. Each compound was tested in duplicate and the dose-response curves were fitted by Prism 5 software (GraphPad, San Diego, CA, USA) using nonlinear least square regression in a sigmoidal model with variable slope.

\section{Statistical analysis}

The results were analyzed using Prism 5 (GraphPad) and representatives of three independent experiments in duplicate.

$$
\begin{aligned}
& Z^{\prime}=1-3 \times \frac{\left(\mathrm{SD}_{\mathrm{PC}}+\mathrm{SD}_{\mathrm{NC}}\right)}{\left|\mathrm{M}_{\mathrm{PC}}-\mathrm{M}_{\mathrm{NC}}\right|} \\
& \text { Inhibition } \%=\left(1-\frac{\text { Signal }_{\text {test }}-\text { Signal }_{\mathrm{NC}}}{\text { Signal }_{\mathrm{PC}}-\text { Signal }_{\mathrm{NC}}}\right) \times 100 \%
\end{aligned}
$$

$\mathrm{PC}$ indicates the average of cells in positive control wells, and $\mathrm{NC}$ indicates the average of cells in negative control wells.

\section{Results}

The GPR139 agonist compound 1 was employed to screen antagonists of GPR139. A total of 16000 compounds with diverse structures were screened at $10 \mu \mathrm{mol} / \mathrm{L}$ in the presence of $100 \mathrm{nmol} / \mathrm{L}$ of compound $\mathbf{1}$ using a calcium mobilization assay. The $Z^{\prime}$ of the screening assay was 0.74 with an $S / B$ ratio of 22 and a coefficient of variation (CV) value of $5.0 \%$ (Figure 2 ). These parameters suggest that the assay system is of high quality and is suitable for HTS ${ }^{[10]}$. The scatter plots of HTS are shown in Figure 3.

In the primary screening, 162 hits were identified $(\geq 50 \%$ inhibition of compound $\mathbf{1}$ induced activation). Five hits were subsequently confirmed (Figure 4) in dose-response assays.

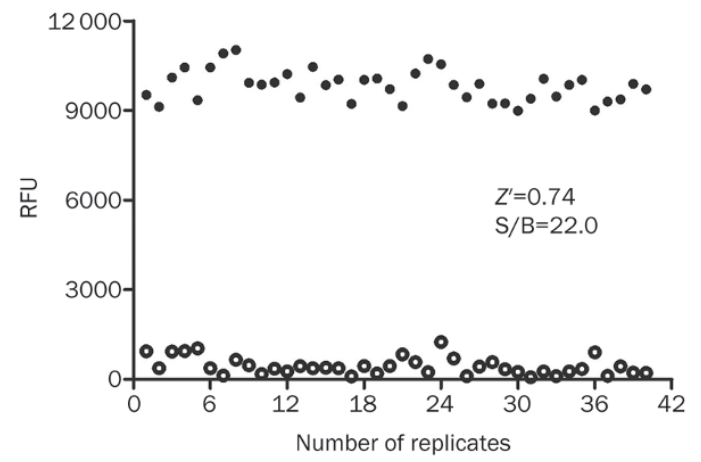

Figure 2. Z' value and S/B ratio determination. The assay was performed under optimized conditions with GPR139-expressing CHO-K1 cells. The background (open circles) indicates the relative fluorescence units in $0.5 \%$ DMSO. The signal (closed circles) indicates the relative fluorescence units in $100 \mathrm{nmol} / \mathrm{L}$ of compound 1 . Forty replicates of the $\mathrm{S} / \mathrm{B}$ readouts were examined. RFU=relative fluorescence units.

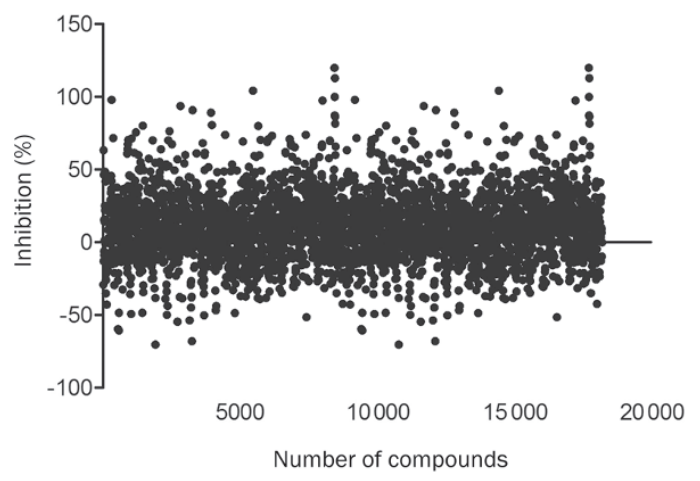

Figure 3. HTS of 16000 small molecule compounds using a calcium mobilization assay. The results are expressed as the percentage of inhibition of each sample on calcium mobilization responses induced by the GPR139 agonist compound 1.
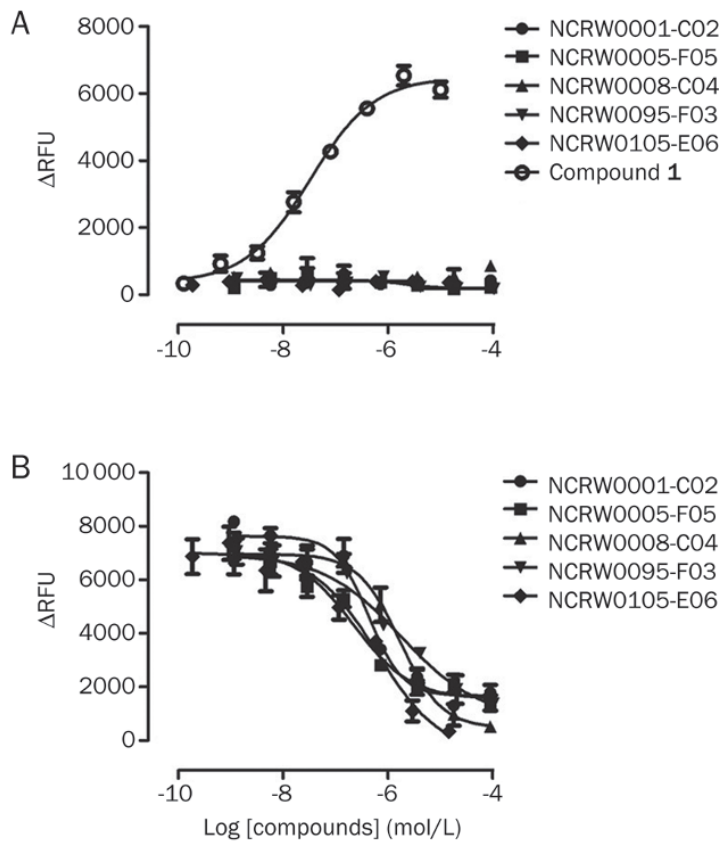

Figure 4. Concentration-dependent characteristics of the five confirmed hits. (A) The calcium mobilization responses of NCRW0001-C02 $(\bullet)$, NCRW0005-F05 (•), NCRW0008-C04 ( $\boldsymbol{\Delta}$ ), NCRW0095-F03( $\boldsymbol{\nabla}$ ), NCRW0105-E06 ( ) and compound $\mathbf{1}(0)$ in CHO-K1 cells stably transfected with human GPR139. (B) Antagonism of NCRW0001-C02 (•), NCRW0005-F05 (घ), NCRW0008-C04 ( $\mathbf{\Delta})$, NCRW0095-F03 ( $\mathbf{\nabla})$ and NCRW0105-E06 ( $)$ to compound 1 induced calcium mobilization. The $\mathrm{IC}_{50}$ values were calculated by nonlinear regression analysis of the doseresponse curves generated using the Prism 5 program. All data points are representative of three independent experiments performed in duplicate.

They represent 4 different structural scaffolds; NCRW0001C02 and NCRW0005-F05 share the same core and their $\mathrm{IC}_{50}$ values are similar $(0.2$ and $0.4 \mu \mathrm{mol} / \mathrm{L}$, respectively). The other 3 confirmed hits, namely NCRW0008-C04, NCRW0095F03, and NCRW0105-E06, showed variable antagonist activities with $\mathrm{IC}_{50}$ values ranging from 0.4 to $2.1 \mu \mathrm{mol} / \mathrm{L}$ (Table 1 ). 
Table 1. Confirmed hits showing consistent antagonistic effects on GPR139 agonist compound 1 and their corresponding structures. $I_{50}$ values are mean \pm SEM. $n=3$.

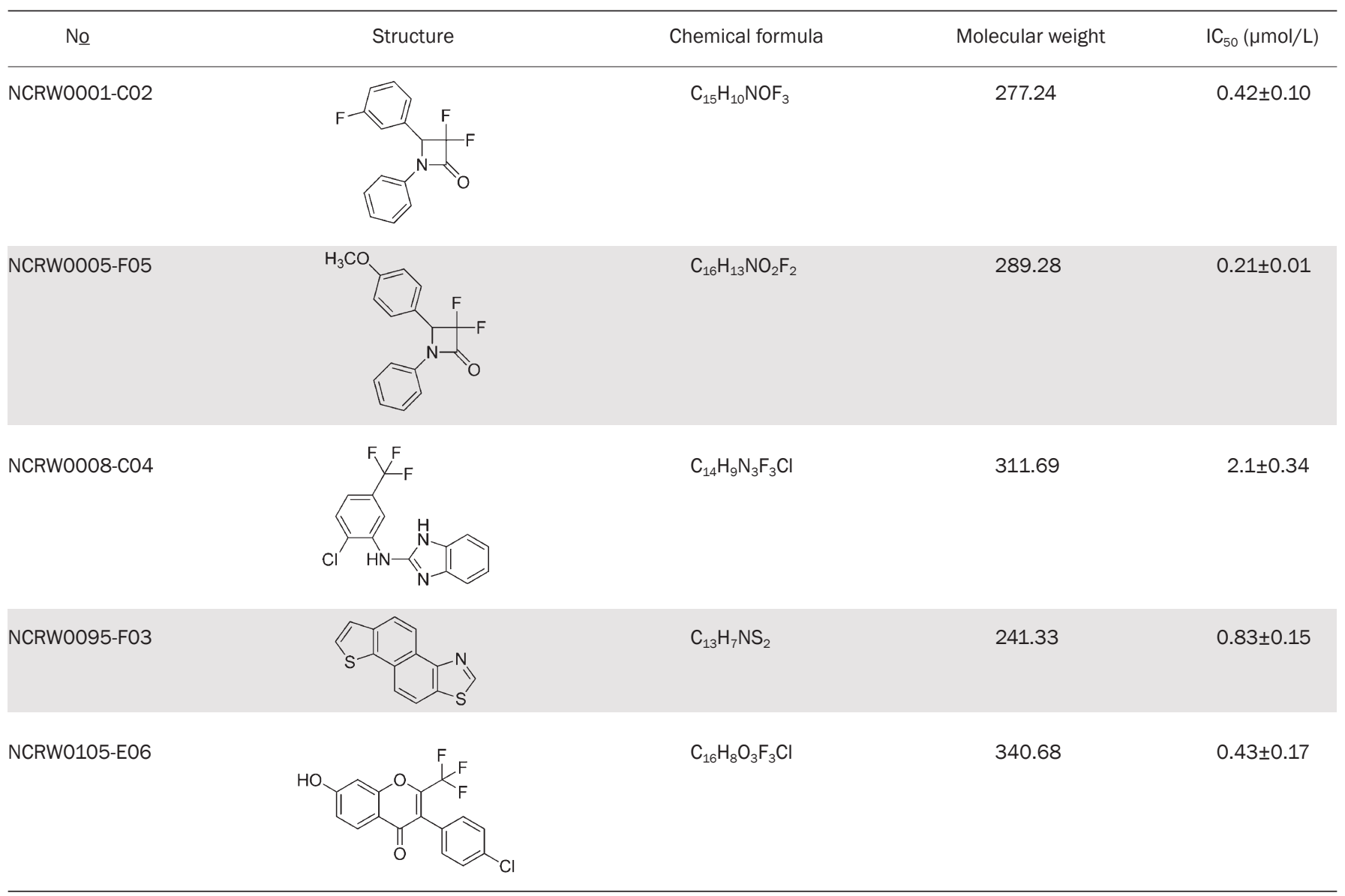

\section{Discussion}

GPR139 was identified by searching the genomic database and has characteristics of the rhodopsin family of GPCRs ${ }^{[3]}$. It is abundantly expressed in distinct regions of the brain, both in humans and in mice. In the caudate putamen, habenular nucleus, zona incerta and medial mammillary nucleus, the expression of GPR139 is higher than that in the thalamus, amygdala and spinal cord ${ }^{[2,3]}$, which suggests a significant role of GPR139 in the CNS.

GPR139 was first reported as a Gq-coupled receptor ${ }^{[2,3]}$. Matsuo et al overexpressed GPR139 in 293-EBNA cells and found that it was capable of activating serum response factor mediated transcription. Additionally, this reaction could be inhibited by a $\mathrm{G}_{\mathrm{q} / 11}$ selective inhibitor ${ }^{[2]}$. This observation was confirmed through the discovery of a series of GPR139 agonists using calcium mobilization assays ${ }^{[7,8]}$. Susens et al identified the signal transduction pathway using both $\mathrm{Ca}^{2+}$ mobilization and luciferase-reporter-gene assays. They proposed that GPR139 was coupled to an inhibitory G-protein and mediated by phospholipase $C^{[3]}$. However, Hu et al identified GPR139 as a Gs-coupled receptor because overexpressed GPR139 in HEK239 cells could increase basal intracellular cAMP con- centrations $^{[6]}$. Previous studies have shown that Gq-coupling is the main signaling pathway of GPR139 and might activate other pathways ${ }^{[8]}$. Furthermore, it was noted that GPR139 appears to be a monomer in HEK-293 cells and a dimer in CHO-K1 cells ${ }^{[3]}$.

In this study, we described an HTS assay to screen antagonists to GPR139 based on intracellular calcium influx and identified a series of small molecule hits that blocked the activity of GPR139 induced by compound $\mathbf{1}$. All of the compounds showed reasonable potencies (close or below $2 \mu \mathrm{mol} / \mathrm{L}$ ), of which two compounds (NCRW0001-C02 and NCRW0005F05) possessed the same core region consisting of 3,3-difluoro4-phenylazetidin-2-one. A preliminary structure-activity study suggested that substitution of electron-donating groups on the phenyl group was beneficial for antagonistic effects. These compounds showed little similarity to the structures of antagonists previously reported. Our findings thus offer novel structures and provide promising tools in the study of both the signaling pathway(s) and physiological significance of this orphan receptor.

In summary, we conducted an HTS study based on intracellular calcium influx and identified five small-molecule antago- 
nists that blocked the activity of GPR139 agonist compound 1. Our discovery supports the claim that GPR139 is a $\mathrm{Ga}_{\mathrm{q}}-$ coupled receptor.

\section{Acknowledgements}

This work was partially supported by grants from the National Health and Family Planning Commission of China (2012ZX09304-011, 2013ZX09401003-005, 2013ZX09507001, and 2013ZX09507-002), the Shanghai Science and Technology Development Fund (13DZ2290300), H Lundbeck A/S Denmark and the Thousand Talents Program in China.

\section{References}

1 Bockaert J, Pin JP. Molecular tinkering of G protein-coupled receptors: an evolutionary success. EMBO J 1999; 18: 1723-9.

2 Matsuo A, Matsumoto S, Nagano M, Masumoto K, Takasaki J, Matsumoto $\mathrm{M}$, et al. Molecular cloning and characterization of a novel Gq-coupled orphan receptor GPRg1 exclusively expressed in the central nervous system. Biochem Biophys Res Commun 2005; 331: 363-9.

3 Susens U, Hermans-Borgmeyer I, Urny J, Schaller HC. Characterisation and differential expression of two very closely related G-proteincoupled receptors, GPR139 and GPR142, in mouse tissue and during mouse development. Neuropharmacology 2006; 50: 512-20.
4 Gloriam DEl, Schioth HB, Fredriksson R. Nine new human Rhodopsin family G-protein coupled receptors: Identification, sequence characterisation and evolutionary relationship. Biochim Biophys Acta 2005; 1722: 235-46.

5 Vanti WB, Nguyen T, Cheng R, Lynch KR, George SR, O'Dowd BF. Novel human G-protein-coupled receptors. Biochem Biophys Res Commun 2003; 305: 67-71.

6 Hu LA, Tang PM, Eslahi NK, Zhou T, Barbosa J, Liu Q. Identification of surrogate agonists and antagonists for orphan G-protein-coupled receptor GPR139. J Biomol Screen 2009; 14: 789-97.

7 Shi F, Shen JK, Chen DA, Fog K, Thirstrup K, Hentzer M, et al. Discovery and SAR of a series of agonists at orphan $G$ protein-coupled receptor 139. ACS Med Chem Lett 2011; 2: 303-6.

8 Isberg V, Andersen KB, Bisig C, Dietz GP, Brauner-Osborne H, Gloriam $D E$. Computer-aided discovery of aromatic $L$-alpha-amino acids as agonists of the orphan G protein-coupled receptor GPR139. J Chem Inf Model 2014; 54: 1553-7.

9 Lipinski CA, Lombardo F, Dominy BW, Feeney PJ. Experimental and computational approaches to estimate solubility and permeability in drug discovery and developemt settings. Adv Drug Deliv Rev 2001; 46: 3-26.

10 Zhang JH, Chung TD, Oldenburg KR. A simple statistical parameter for use in evaluation and validation of high throughput screening assays. J Biomol Screen 1999; 4: 67-73. 